\title{
In memory of professor Weixing Wan
}

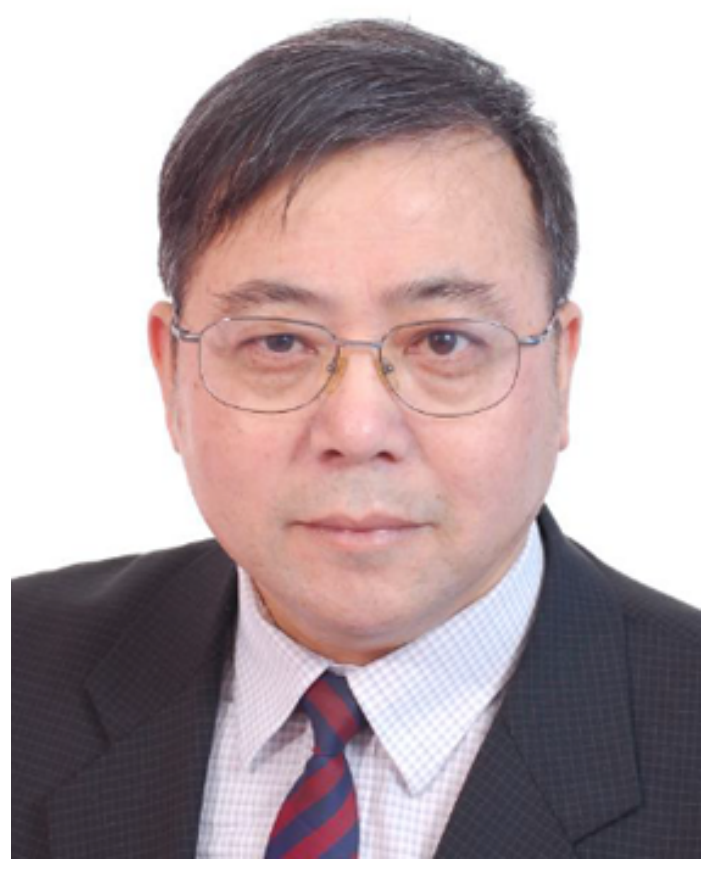

$\mathrm{O}$ n May 20, 2020, Professor Weixing Wan of the Institute of Geology and Geophysics, Chinese Academy of Sciences (IGGCAS), a world renowned space scientist and planetary physicist, passed away at age of 62 . Prof. Wan was an academician of the Chinese Academy of Sciences (CAS). He served as a member of the $13^{\text {th }}$ National People's Congress Standing Committee, and of the $14^{\text {th }}$ Central Committee of Jiusan Society. He also served as the chief scientist of China's first Mars exploration mission, Tianwen-1, and the director of the Key Laboratory of Earth and Planetary Physics of the CAS. His passing is a great loss to the science community. This article was especially written in memory of him.

Weixing Wan was born in Tianmen, Hubei Province, on July 1 , 1958. In 1978, he was admitted to the Department of Space Physics of Wuhan University. After graduation in 1982, he joined the Wuhan Institute of Physics (WIP) in the CAS, under the supervision of Prof. Jun Li, a space physicist and CAS academician. Mr. Wan obtained his master's and doctor's degrees in space physics in 1984 and 1990, respectively. He then was appointed as deputy research professor and research professor in the WIP in 1990 and 1994, respectively. He served as director of Wuhan lonospheric Observatory (WIO) from 1994 to 2004. He was appointed to a research professorship in the IGGCAS and served as director of the Geomagnetism and Space Physics Laboratory since 2004. In 2012, Prof. Wan established the Key Laboratory of lonospheric Space Environment of the CAS and served as its first director. In 2014, he was appointed director of the Key Laboratory of Earth and Planetary Physics of the CAS.

The National Natural Science Foundation of China honored Prof. Wan with a Distinguished Young Scholars award in 1995; in 2011 he was elected to be the academician of the Chinese Academy of Sciences. Academician Wan also served as vice president of the Chinese Society of Space Research in 2016, and as executive vice president of the Chinese Geophysical Society in 2017.

Prof. Wan was a space scientist with profound academic attainments. He engaged for many years in theoretical, observational, and applied research in the fields of ionosphere physics, ionospheric radio propagation, and upper atmosphere physics and made fruitful contributions to all those fields, including a series of breakthroughs in local characteristics of ionospheric disturbances over China, and in our understanding of atmosphere-ionosphere coupling and solar wind-magnetosphere-ionosphere coupling. The theoretical model of the ionosphere thermosphere developed by his team reaches the international advanced level. He took the lead in ionospheric nowcast and prediction based on data assimilation, which advanced the development of numerical ionosphere studies in China. In 1989, the CAS's second prize for natural science research was awarded for work on generalized ray inversion of ionospheric disturbance profile that was based on results published in Prof Wan's postgraduate thesis. Prof. Wan participated in research on short-wave self-tuning clocks, which won first prize in the 1995 Hubei Provincial Award for Science and Technology Progress. In 2004, research led by Prof. Wan into ionospheric time delay correction technology and methodology won second prize awarded by Military award for Science and Technology Progress. In 2015, Prof. Wan and his team won second prize in National Award for Natural Sciences as the leading scientist, honoring his achievements in explaining the "driving process of ionospheric variability". In 2017, Prof. Wan won the Ho Leung Ho Lee Foundation Prize for Scientific and Technological Progress.

Prof. Wan was a great academic leader with excellent charisma. He inherited and carried forward the academic tradition of ionospheric research in China, and greatly enhanced the international reputation and influence of Chinese ionospheric research, which originated in the 1940s when Prof. C. T. Kwei established an ionospheric observing station in Wuhan. The station was taken over by the Institute of Geophysics of the CAS in 1957. It was later transferred to the WIP and became the ionospheric research laboratory. In 1994, Prof. Jun Li, who was the academic leader of the laboratory, suddenly died. After his death, a large number of other key personnel departed from the laboratory. Prof. Wan was appointed laboratory director at this difficult juncture. After ten years of dedicated effort, his laboratory 
had become the most powerful ionospheric research team in China. In 2004, according to the discipline integration requirements of the CAS, Prof. Wan led his team to join the IGGCAS and served as director of the Geomagnetism and Space Physics Laboratory. After several years, the laboratory had developed into one of the world's most active research teams in the field of space physics, ranking number one in the world, for many consecutive years, as measured by the number of papers published in the Journal of Geophysical Research. The number of papers published since 2000 with key words "ionosphere" and "thermosphere" that were co-authored by Prof. Wan also ranks first in the world. In 2012, under his leadership, Prof. Wan's laboratory passed the CAS's acceptance review and became the new first place key laboratory of China in the geoscience field, the "Key Laboratory of the lonospheric Space Environment of CAS". In 2014, the Key Laboratory of Ionospheric Space Environment and the Key Laboratory of the Earth's Deep Interior were merged to establish the "Key Laboratory of Earth and Planetary Physics of CAS". Prof. Wan served as the director of the combined laboratories, and once again won the first place in the geoscience field in the evaluation of that year.

As an advocator and practitioner of "independent research" in space physics in China, Prof. Wan paid significant attention to the development of observing technology and facility. He led and actively participated in the construction of the Mohe-BeijingWuhan-Sanya space environment observation meridian chain. It was he who proposed developing the most advanced large phased array of incoherent scatter radar in Sanya in 2013; this proposal was soon funded, in 2014 , by the Natural Science Foundation of China through a major scientific instrument development project. The radar project aims to study major scientific issues such as low latitude atmosphere ionosphere magnetosphere coupling, regional characteristics of the ionosphere in East Asia, and the irregularity and scintillation in southern China. It will significantly enhance China's ground based ability to detect details of the space environment of China, bringing China's ionospheric research level into international advanced ranks. Prof. Wan was devoted to the project. He led the team to analyze and evaluate each key issue in the design of the system, carried out many of investigations, and solved key technical problems such as multi-condition incoherent scatter theory spectrum analysis and low-noise digital transceiver and weak signal processing. The Sanya Incoherent Scatter Radar (SYISR) project will be completed by the end of 2020 .

Prof. Wan was a pioneer and founder of planetary physics, and significantly promoted the development of planetary science in China. According to the developing trend of international planetary science and the Chinese national strategic plan, he proposed an innovative way of deep integration of planetary science research and deep space exploration engineering with Chinese characteristics, which has made a pioneering and significant contribution to the development of space science and planetary science in China. As the principal investigator (PI) of China's first Mars exploration mission, Tianwen-1, he organized a national team consisting of top planetary scientists, which opened the way for the scientific community and the engineering community to work together directly to serve the national strategy. He founded the Key Laboratory of Earth and Planetary Physics of CAS and the Planetary Physics Professional Committee of the Chinese Geophysical Society. He actively promoted the construction of the prime subject of planetary science in China. He presided over establishment, in the College of Earth and Planetary Sciences, University of Chinese Academy of Sciences, of courses relevant to planetary physics. His work raised the curtain for the training of future generations of talent in planetary physics in China. Prof. Wan proposed a complete set of planetary exploration plans, on the basis of observations from Earth, near Earth, space stations, the moon, and spacecraft, which form a roadmap for Chinese planetary exploration in line with the current situation of China.

Prof. Wan paid great attention to the development of China's space science and planetary physics journals. He served as the deputy chief editor of Science China-Earth Science, Chinese Science Bulletin, and the Chinese Journal of Space Science, and he was a member of the editorial board of the Chinese Journal of Geophysics. Prof. Wan made important contributions to the development of these journals. He also helped to create the first Chinese planetary journal published in English, Earth and Planetary Physics (EPP), and served as its first editor-in-chief. His leadership accelerated the international development of EPP and provided an important platform for the international communication of scientific research achievements by Chinese and international teams in space science and planetary physics.

Prof. Wan was an outstanding educator. He attached great importance to the cultivation of students and was good at teaching according to his student's aptitudes. He was rigorous in his study and tireless in teaching. He not only had strict requirements for students, but also cared for and understood students. His students found him open-minded, wise, amiable, and concerned about their development. He trained a large number of excellent scientists and made great contributions to the development of education for China.

Prof. Wan's style of study was rigorous in his whole life. He was open, self-disciplined, lenient, willing to contribute, and indifferent to fame and wealth. He dedicated his life to the country and the people; he was tireless in advancing his science and technology, which for him were his primary mission. Prof. Weixing Wan's life is a splendid chapter in the history of the motherland. He has set a brilliant example for us. Prof. Wan will long be remembered with a sense of loss and warm appreciation.

Chinese Geophysical Society

Published online: 6 July 2020 https://doi.org/10.26464/epp2020051 